\title{
Oxidative stress, obstructive sleep apnea and cardiovascular disease
}

\author{
Ilker Tasci
}

Received: 7 June 2011 /Revised: 22 June 2011 / Accepted: 23 June 2011 /Published online: 1 July 2011

(C) Springer-Verlag 2011

To the editor:

I read with great interest the article by Lee et al. concluding with no association of oxidative stress to hypoxia or sleep disturbances in patients with obstructive sleep apnea [1], while several very recent studies demonstrated increase in circulating markers of oxidative stress in people with this condition [2,3]. Moreover, improvement in oxidative stress markers with appropriate continuous positive airway pressure therapy was also demonstrated [4]. Therefore, some unanswered issues remain with regards to the study by Lee et al. and the statistical models used in there. As the authors mention in their paper, the data are somewhat controversial whether OSA itself results in oxidative stress or it is simply a consequence of comorbidities. To clarify this, one would prefer enrolling a totally healthy group matched for age or age and body mass index only. In this context, the control group in the study by Lee et al., as they call "normal", seems not healthy with respect to several parameters. Basically, the mean fasting plasma glucose in the control group shows that most of them were in the prediabetic state. The information whether an oral glucose tolerance test was performed to exclude diabetes is also lacking in the text. The effects of high blood glucose level in this group are also reflected by the similar or slightly higher blood insulin level and HOMA scores in comparison with the patient groups. Several authors

\section{Tasci}

Gulhane School of Medicine, Department of Internal Medicine and Geriatrics,

Ankara, Turkey

I. Tasci $(\bowtie)$

GATA Geriatri Bilim Dali,

Etlik,

06018 Ankara, Turkey

e-mail: itasci@gata.edu.tr have reported increased circulating levels of oxidative stress markers in people with prediabetes [5, 6]. Therefore, in the present study, inclusion of an insulin-resistant group was likely to encounter a confounding effect on the results, which was also not used in the model while performing a regression analysis. Moreover, some of the patients seem clearly hypertensive, i.e., the term "mildly hypertensive" above 140/ $90 \mathrm{mmHg}$ may not be appropriate. Finally, taking the whole subjects with OSA as one group would give more powerful results, especially when more appropriate and healthy controls were included.

Conflict of interest None

\section{References}

1. Lee SD, Ju G, Choi JA, Kim JW, Yoon IY (2011) The association of oxidative stress with central obesity in obstructive sleep apnea. Sleep Breath. doi:10.1007/s11325-011-0536-7

2. Christou K, Markoulis N, Moulas AN, Pastaka C, Gourgoulianis KI (2003) Reactive oxygen metabolites (ROMs) as an index of oxidative stress in obstructive sleep apnea patients. Sleep Breath 7:105-110

3. Vatansever E, Surmen-Gur E, Ursavas A, Karadag M (2010) Obstructive sleep apnea causes oxidative damage to plasma lipids and proteins and decreases adiponectin levels. Sleep Breath. doi:10.1007/s11325-010-0378-8

4. Celec P, Hodosy J, Behuliak M, Pálffy R, Gardlík R, Halčák L, Mucska I (2011) Oxidative and carbonyl stress in patients with obstructive sleep apnea treated with continuous positive airway pressure. Sleep Breath. doi:10.1007/s11325-011-0510-4

5. Su Y, Liu XM, Sun YM, Jin HB, Fu R, Wang YY, Wu Y, Luan Y (2008) The relationship between endothelial dysfunction and oxidative stress in diabetes and prediabetes. Int J Clin Pract 62:877-882

6. Lim SC, Tan HH, Goh SK, Subramaniam T, Sum CF, Tan IK, Lee BL, Ong CN (2006) Oxidative burden in prediabetic and diabetic individuals: evidence from plasma coenzyme Q(10). Diabet Med 23:1344-1349 